\title{
Classic Kaposi's sarcoma and involvement of the small intestine as shown by capsule endoscopy
}

A 65-year-old HIV-negative man presented at the Dermatology Department of our Hospital with skin lesions typical of classic Kaposi's sarcoma. Although he was asymptomatic as regards the gastrointestinal tract he underwent gastroscopy and colonoscopy, as Kaposi's sarcoma can affect the gastrointestinal mucosa. Indeed, protruding red lesions at the duodenum ( Fig. 1) and the colonic mucosa ( $\bullet$ Fig. 2) were noted. The patient then underwent small-bowel capsule endoscopy, which revealed even more prominent lesions in the jejunum ( $\bullet$ Fig. 3), as well as ulcerated ones in the ileum ( $\bullet$ Fig. 4). Kaposi's sarcoma has been classified into four clinical variants: classic or Mediterranean; endemic or African; epidemic or AIDS-related; iatrogenic or immunosuppression-related $[1,2]$. Human herpesvirus 8 (HHV-8), has been found in all these variants.

Classic Kaposi's sarcoma, as originally described, was a relatively indolent disease affecting elderly men from the Mediterranean region, or those of Eastern European descent. Kaposi's sarcoma are nodules or blotches that may be red, purple, brown, or black, and are usually papular (i.e. palpable or raised). They are typically found on the skin, but spread elsewhere is common, especially the mouth, gastrointestinal tract, and respiratory tract. Gastrointestinal lesions may be silent or may cause weight loss, pain, nausea/ vomiting, diarrhea, bleeding, malabsorption, or intestinal obstruction. Reports of gastrointestinal Kaposi's sarcoma in the literature are sparse, and according to our knowledge small-bowel classic Kaposi's sarcoma has only been reported once before in a Peruvian journal [3]. It may be that small-bowel lesions were undetectable, as up to the advent of capsule endoscopy there were no means of visualizing the small intestine. Our case suggests that the small bowel should also be investigated in patients with Kaposi's sarcoma, as even more prominent lesions than those seen in the rest of the gastrointestinal tract can be detected.

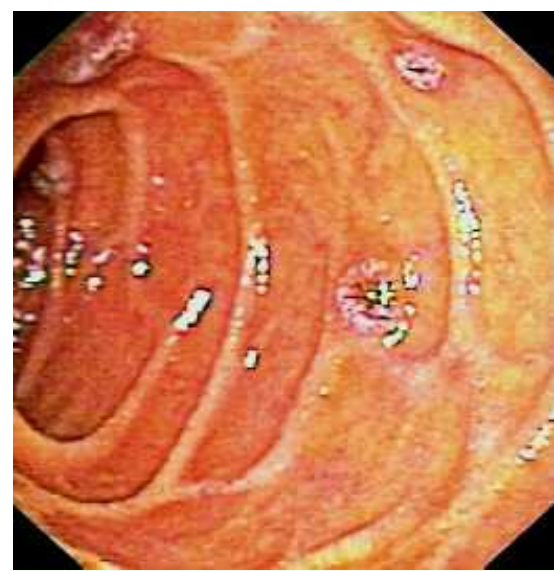

Fig. 1 Kaposi's sarcoma of the duodenum.

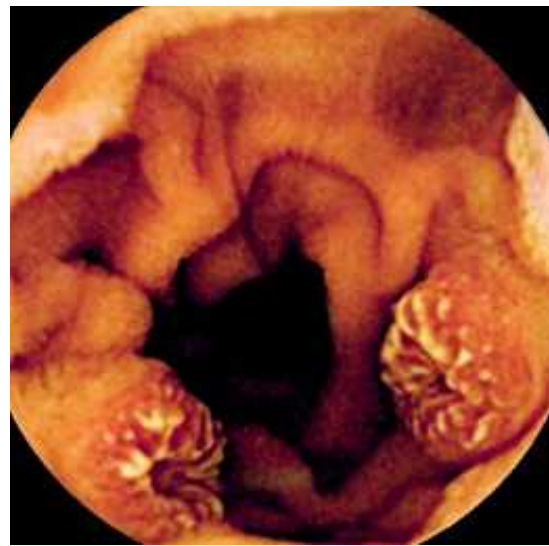

Fig. 3 Kaposi's sarcoma of the jejunum.

\section{N. Viazis, J. Vlachogiannakos,}

D. Georgiadis, M. Rodias, C. Noutsis, D. G. Karamanolis

2nd Department of Gastroenterology, Evangelismos Hospital, Athens, Greece

\section{References}

1 Antman K, Chang Y. Kaposi's sarcoma. New Engl J Med 2000; 342: 1027-1038

2 Szajerka T, Jablecki J. Kaposi's sarcoma revisited. AIDS Rev 2007; 9: 230-236

3 Mohanna S, Sanchez J, Ferrufino J et al. Classic Kaposi sarcoma in jejunum: case report. Rev Gastroenterol Peru 2005; 25: 285-287

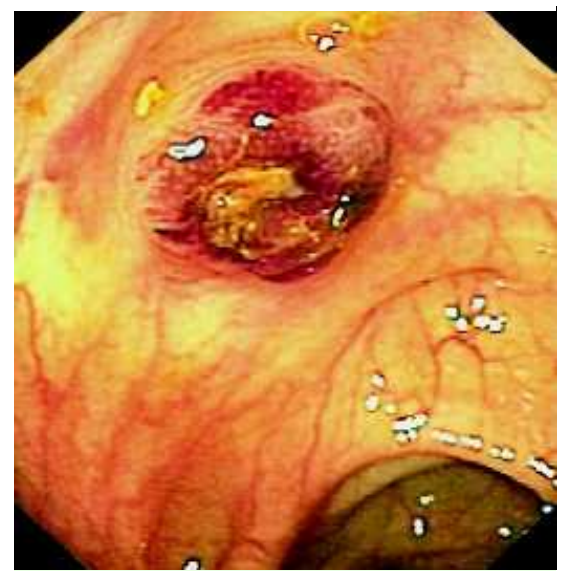

Fig. 2 Kaposi's sarcoma of the colon.

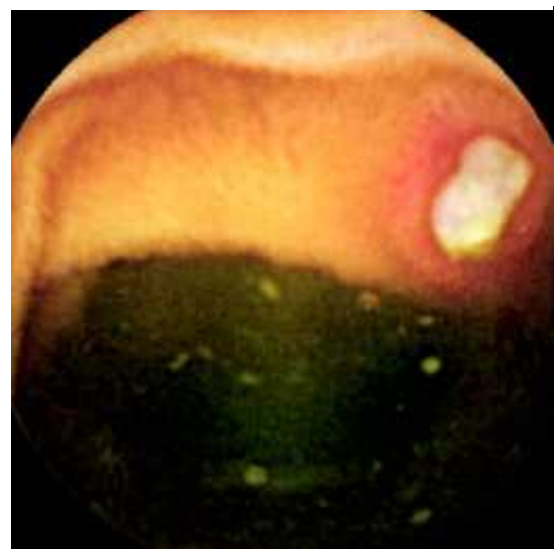

Fig. 4 Ulcerated Kaposi's sarcoma of the ileum.

Bibliography

DOI 10.1055/s-2008-1077467

Endoscopy 2008; 40: E209

(c) Georg Thieme Verlag KG Stuttgart · New York . ISSN 0013-726X

Corresponding author

N. Viazis, MD

2nd Department of Gastroenterology,

Evangelismos Hospital

59 Niriidon Street

17561 P. Faliro

Athens

Greece

Fax: +30-210-7233671

Nikos.Viazis@gmail.com 